\title{
O PROGRAMA BOLSA FAMÍLIA EM CIDADES PEQUENAS DO NORDESTE DO BRASIL: O CASO DE ALCÂNTARAS E FRECHEIRINHA/CE
}

\author{
The Bolsa Familia program in small cities of northeast Brazil: the case of Alcâtaras and \\ Frecheirinha / CE
}

\section{El programa Bolsa Familia en pequeñas ciudades del Noreste de Brasil: el caso de Alcâttaras y Frecheirinha / CE}

\footnotetext{
1 Mestrando do Curso de Pós-graduação em Geografia da Universidade Estadual Vale do Acaraú UVA - Brasil e-mailbertoni.77@hotmail.com.

2 Doutora em Geografia pela Universidade Federal do Rio Grande do Norte -UFRN- Brasil; Professora Adjunta do Curso de Geografia da Universidade Estadual Vale do Acaraú - UVA- Brasil, e-mail- virginiaholand@ hotmail.com.
}

\section{Resumo}

O presente trabalho é um estudo sobre os impactos do Programa Bolsa Família (PBF) em duas cidades pequenas da Região Metropolitana de Sobral: Alcântaras e Frecheirinha. Para a realização desta pesquisa, realizamos trabalhos de campo e aplicação de questionários. São duas cidades com predomínio de atividades econômicas distintas. No entanto observamos que o PBF representa uma importante fonte de rendimento as famílias das duas cidades, que é utilizado na aquisição de bens e serviços, aumentando também o seu poder de compra, que por sua vez estimula a produção dos setores de atividades. Essa rotatividade tem impulsionado a economia gerando emprego e renda no comércio local e nas cidades vizinhas, impactando na vida de beneficiários e não beneficiários.

Palavras-chave: Cidades pequenas. Programa Bolsa Família. Beneficiários.

\begin{abstract}
The present paper is a study about the impacts of the Bolsa Família Program (PBF) in two small cities of the Sobral Metropolitan Region: Alcântaras and Frecheirinha. We conducted field research and application of questionnaires for this work. They are two cities with predominance of distinct economic activities. However, we note that the PBF represents an important source of income for the families of both cities, which is used to purchase goods and services, also increasing their purchasing power, which in turn stimulates the production of the activity sectors. This turnover has driven the economy by generating jobs and income in local businesses and surrounding cities, impacting the lives of beneficiaries and nonbeneficiaries.
\end{abstract}

Keywords: Small Towns. Bolsa Família Program. Beneficiaries. 


\section{Resumen}

El presente trabajo es un estudio sobre los impactos del Programa Bolsa Família (PBF) en dos pequeñas ciudades de la Región Metropolitana de Sobral: Alcântaras y Frecheirinha. Para llevar a cabo esta investigación, realizamos trabajo de campo y aplicación de cuestionarios. Son dos ciudades con predominio de distintas actividades económicas. Sin embargo, observamos que el PBF representa una fuente importante de ingresos para las familias de ambas ciudades, que se utiliza para comprar bienes y servicios, y también aumenta su poder adquisitivo, lo que a su vez estimula la producción de los sectores de actividad. Esta rotación ha impulsado la economía al generar empleo e ingresos en las empresas locales y las ciudades circundantes, impactando las vidas de los beneficiarios y no beneficiarios.

Palabras clave: Ciudades pequenas. Programa Bolsa Família. Beneficiarios.

Recebido em: 18/10/2019

Aceito para publicação em: 05/12/2019

\section{Introdução}

O presente estudo se baseia na premissa de que o Programa Bolsa Família (PBF) é um importante programa social no combate a pobreza, possibilitando, por meio de suas condicionalidades, que as famílias beneficiárias possam acessar os direitos básicos como saúde e educação. Compreender como esse programa social tem impactado na vida das famílias beneficiárias, sob o prisma do repasse monetário, é de suma importância. Diante disso, nossa reflexão análisa os impactos do PBF em duas cidades pequenas do Noroeste cearense.

Em linhas gerais, o PBF é um programa de transferência de renda brasileiro criado pelo Presidente Luís Inácio Lula da Silva, em 2003, tendo como prioridade as famílias que estão em situação de pobreza e extrema pobreza, em todo território nacional. Nos últimos anos, o PBF tem gerado uma série de discussões, tais como: quais os reais efeitos do programa para a redução da pobreza? Não haveria um caráter assistencialista que acaba por beneficiar seus idealizadores? Como o programa contribui para a mudança dos hábitos de consumo da população mais pobre?

Não buscamos resposta a todos esses questionamentos, mas, percebemos que discuti-los, no âmbito das cidades pequenas, nos ajuda a entender o funcionamento do PBF para além das estatísticas. Nesse sentido, analisamos o impulso da transferência de renda do PBF na vida de duas famílias: uma na cidade de Alcântaras e outra na cidade 
de Frecheirinha. Procuramos verificar se é possível observar mudanças, nos últimos cinco anos, no que tange o poder de consumo das famílias após inserção no Programa e se os recursos repassados pelo governo federal são realmente eficazes no combate a pobreza.

A metodologia adota para o desenvolvimento da presente pesquisa tem por base a realização de levantamento bibliográfico, documental e a consulta a dados secundários em fontes oficiais, junto ao Centro de Assistência Social - CRAS - das duas cidades: pagina oficial do Instituto Brasileiro de Geografia e Estatística (IBGE), pagina oficial do Ministério do Desenvolvimento Social e Combate à Fome (MDS) e observações diretas. Além disso, realizamos trabalhos de campo, aplicando nas duas cidades, questionários com perguntas abertas. Usaremos nomes fictícios para preservar a identidade dos entrevistados.

\section{O Programa Bolsa Família na vida dos brasileiros}

O PBF é a expressão atual do desenvolvimento dos programas de transferência de renda no Brasil. Produto de um processo iniciado em nível municipal, no ano de 1995, com experiências pioneiras em Campinas, Ribeirão Preto, Santos e São Paulo, e da experiência do Bolsa Escola de Brasília (GUILHON; SILVA, M. 2014). Hoje, o Programa está presente em todos os municípios brasileiros.

Eleito Presidente da República, Luis Inácio Lula da Silva com dois mandatos consecutivos (2003 a 2010), ciente dos graves problemas decide unificar os programas existentes (PET, Bolsa Escola, Bolsa Alimentação, Cartão Alimentação e agregando também o Vale Gás), criando o PBF, instituído pela medida provisória ${ }^{\circ}$. 132 de 20 de outubro de 2003, transformada em Lei $\mathrm{n}^{\circ}$. 10. 836 de 09 de janeiro de 2004, regulamentada pelo Decreto $n^{\circ}$. 5. 209 de 17 de setembro de 2004. Com a unificação, acabou a disparidade que existia entre os programas, sendo repassado o mesmo valor para todas as regiões. Essa estratégia possibilitou que os beneficiários de diferentes regiões tivessem os mesmos direitos.

A integração buscou superar as limitações que os programas tinham isoladamente. Cada programa apresentava sua própria estrutura administrativa, sua forma especifica de selecionar os beneficiários. Essa desarticulação entre os programas contribuía para a sua ineficiência (SANTANA, 2007). 
Com a unificação, o programa passou a ser coordenado pela Secretaria Nacional de Renda e Cidadania (Senarc), sob-responsabilidade do Ministério do Desenvolvimento Social e Combate à Fome (MDS). O pacote de vários programas em um só fez do PBF o quarto maior programa do país, ficando atrás apenas do Sistema Único de Saúde (SUS), da Educação e da Previdência Social.

"É um programa de transferência de renda que visa atender as famílias em situação de extrema pobreza, cuja renda per capita é menor que $\mathrm{R} \$ 85,00$ ou aquelas em estado de pobreza, que possuem renda per capita de $\mathrm{R} \$ 85,01$ a $\mathrm{R} \$ 170,00 ”$ ". (MDS, 2018) O programa também cobra a responsabilidade das famílias em garantir o acesso de suas crianças e adolescentes à saúde e à educação. As famílias que descumprem as responsabilidades podem sofrer efeitos gradativos que variam desde uma advertência, passando pelo bloqueio e suspensão do benefício.

Essas responsabilidades são conhecidas como condicionalidades: as crianças menores de sete anos devem ser vacinadas e ter acompanhamento de peso e altura; gestantes precisam fazer o pré-natal; crianças e adolescentes de 6 a 15 anos devem ter frequência escolar mínima de 85\%, a cada mês, e os jovens de 16 e 17 anos devem ter frequência escolar mínima de 75\% das aulas, a cada mês. (BRASIL, MDS, 2019).

As condicionalidades do PBF estão presentes na Portaria $n^{\circ}$. 321, de 29 de setembro de 2008, juntamente à Portaria MS/MDS nº. 2. 509 de 18 de novembro de 2004, que regulamenta o compromisso das famílias com à saúde e pela Portaria que regulamenta os compromissos das famílias com a educação MEC/MDS nº. 3. 789, de 17 de novembro de 2004. Cabe aos ministérios da Saúde e da Educação a responsabilidade de fornecer os serviços e fiscalizar a cobrança das condicionalidades.

Em pouco mais de quinze anos de existência, o PBF tem alcançado milhares de brasileiros que viviam na linha de pobreza e extrema pobreza. É um repasse monetário relativamente pequeno, algo em média de $\mathrm{R} \$ 170,00$ para as famílias, mas que faz uma diferença enorme em suas vidas. Conforme o Ministério do Desenvolvimento Social (2019) "O alcance do programa pode ser representado nas cifras dos bilhões. Segundo a Folha de Pagamento do PBF, o valor anual repassado até agosto de 2018 chega a 20. 101. 816. 912,00 bilhões".

Os dados do Instituto de Pesquisa Econômica Aplicada-IPEA (2012) comprovam que entre 2001 a 2011, a renda dos brasileiros mais pobres cresceu 91,2\%. Outro importante estudo é o de Barros et al (2010) que, ao analisar a desigualdade de 
renda no país, tendo como referência os dados do coeficiente de Geni em 2007, constatou ser uma das menores nos últimos trinta anos. São dados importantes que evidenciam que as famílias de baixo poder aquisitivo estão passando por uma ascensão social no espaço de tempo em que foi implantado o PBF em todos os estados da federação.

Seus impactos também são sentidos na educação, é o que mostra Weissheimer (2006) ao constatar que, em pouco mais de três anos de existência do programa, quase 9 milhões de beneficiários entre 6 a 17 anos melhoraram a sua frequência escolar, graças ao sistema de acompanhamento que registra a frequência individual de cada estudante, o que tem impactado diretamente na redução do trabalho infantil no país.

Outro importante estudo é o de Jannuzzi e Pinto (2013) que comprova os efeitos positivos não só na educação, mas também na melhoria das condições de saúde das crianças que têm aumentado o consumo de alimentos: cereais, alimentos processados, carne, leite feijão e açúcar. Constatou-se também que o peso das crianças recémnascidas filhos de mulheres beneficiárias é superior das crianças de mães não beneficiárias.

Como se pode notar, o PBF é um programa que atende as famílias que estão em situação de vulnerabilidade social, procurando, através do repasse monetário, reforçar o compromisso das famílias com a saúde e a educação dos seus filhos, tendo as condicionalidades como um mecanismo de integração social, visando a garantia de condições mínimas para que as famílias assistidas possam ter melhores condições de vida.

\section{A cidade pequena e suas perspectivas com o Programa Bolsa Família}

As pequenas cidades brasileiras são importantes elementos para a investigação científica, pois apresentam um rico conteúdo social, político e econômico. Para compreendê-las, temos que levar em conta não apenas o aspecto quantitativo, mas todo o contexto histórico do processo de urbanização no Brasil e o seu significado nas redes urbanas regionais. Esses pequenos núcleos urbanos não são apenas um aglomerado de ruas e casas, funcionam como células, dando vida e dinâmica aos grandes centros.

As cidades têm suas singularidades, o que torna inviável uma definição simples considerando apenas seus dados quantitativos. O principal aspecto a ser considerado é entender como se dá a composição de sua dinâmica dentro da rede urbana, até porque 
ela não está isolada. A esse respeito, Santos (1994, p. 93) ensina que "nenhum sentido tem o estudo da cidade como um organismo isolado, autônomo". Afinal, as cidades mantêm uma inter-relação, não apenas de vizinhança, mas também de dependência, principalmente com o processo de reorganização espacial que tem reproduzido novos dinamismos em diferentes escalas.

Vivemos em um período caracterizado pela interação da ciência e da técnica, possibilitando a convivência entre o local e o global. O homem começa a fabricar um novo tempo, transgredindo as distâncias, ao mesmo tempo em que acentua as desigualdades. É o período que Santos (2006) chamou de meio técnico-científicoinformacional, marcado pela junção da ciência e a tecnologia junto com a informação, tornando o meio geográfico universal. É universal porque o poder hegemônico se torna cada vez mais presente, buscando a todo custo implantar os mais sutis mecanismos de controle social, alterando as geografias.

Tudo isso gerou as condições ideais que favoreceram o surgimento de uma nova figura política, denominado por Ianni (1999) de 'O príncipe eletrônico', que se sustenta numa complexa rede, articulando mercados e mercadorias, tecnologia e força de trabalho. As corporações cada vez mais sedentas pelo lucro operam em escala global, interessadas na expansão dos mercados. É o dito mundo virtual, que intensifica as articulações e desarticulações, transgredindo livremente as linhas demarcatórias de territórios e fronteiras, impondo astuciosamente novos significados no espaço, alterando-o. O seu principal aspecto é a atuação no nível virtual.

Esse império das técnicas é sentido em todas as escalas, indo desde o pequeno ao grande centro, embora seja em diferentes intensidades; agora são os objetos técnicos que formam o espaço, graças à técnica da informação, permitindo a convergência dos momentos. Os grandes centros ao mesmo tempo em que estão a quilômetros de distância dos pequenos centros, virtualmente, estão mais próximos do que nunca, e não é exagero de Santos (2012, p.26) ao afirmar que "cada lugar tem acesso ao acontecer dos outros". É uma aproximação virtual, mas, ao mesmo tempo, real, agindo sobre o espaço e alterando os comportamentos. Nessa lógica, a pequena cidade aparece como um importante espaço de consumo.

A pequena cidade tem despertado cada vez mais a presença de agentes externos, que têm implantando, nesses espaços, sutis mecanismos psicossociais manipulando consciências, usando a mídia e o marketing como poderosas ferramentas de 
O Programa Bolsa Família em cidades pequenas do Nordeste do Brasil: o caso de Alcântaras e Frecheirinha/CE

DIOGO, B.V.; HOLANDA, V.C.C. de

manipulação social, implantando, nesses espaços, lojas, bancos, mercadorias. Essa dinâmica produzida pelo capital tem suscitado importantes estudos sobre a temática 'pequena cidade' como os de Beajeau-Garnier (1980), Santos (1994), Alegre (1970) dentre tantos outros, ricas fontes de reflexões que constituem um importante conjunto de análises aprofundadas.

É urgente e necessário compreendermos o papel desempenhado pelas pequenas cidades brasileiras nos últimos anos, por fazerem parte de uma complexa rede urbana com suas diferenças e similaridades num país cheio de contrastes e diversidades regionais. As disparidades entre as regiões são atributos que fazem com que a urbanização brasileira seja a materialização de uma complexa interação de fatores causais, com seus diferentes estágios e padrões econômicos e sociais.

Alegre (1970), ao estudar o urbano brasileiro, constata a importância das pequenas cidades no tecido urbano nacional, como responsável por abrigar mais de $40 \%$ da população urbana do país. Ainda segundo o autor, grande parte desses núcleos urbanos apresenta uma precária estrutura econômica, e nem sempre tem a capacidade de oferecer aos moradores funções básicas. Todavia, também encontramos cidades pequenas economicamente dinâmicas, com pesados investimentos que conseguem atender as demandas básicas da sua população, algumas apresentando considerável crescimento demográfico.

Tudo isso reforça a tese deque o tipo de organização e desenvolvimento das pequenas cidades são reflexos do contexto no qual estão inseridas, coexistindo pequenas cidades que reproduzem os mais diversificados cenários: as que têm uma maciça presença de indústrias; as que funcionam como reservatório de mão-de-obra; as pobres; as ricas; as religiosas; as universitárias; as localizadas próximas às cidades médias; próxima aos grandes centros, em fim, são inúmeros os exemplos.

As dinâmicas produzidas nas pequenas cidades mostram que elas não estão ilhadas, muito menos desconectadas dos grandes centros, pelo contrário, cada vez mais, as pequenas cidades estão inseridas no mercado do capital, o que explica a convivência nesses espaços entre o global e o local. Na maioria dos casos, elas servem basicamente como estoque de mão de obra, abastecendo as indústrias instaladas nas grandes e médias cidades.

É o que temos presenciado nas pequenas cidades cearenses, que, nos últimos anos, têm se tornados grandes fornecedoras de mão de obra 'barata' e sem qualificação. 
Eidelwein (2011) chama essa massa de trabalhadores de exército de reserva, sempre na expectativa de uma vaga de emprego. Pode-se dizer que é pouco emprego para muita gente o que, de certa forma, é positivo para as empresas, pois funcionam como pressão para os que estão empregados. Os postos ocupados nessas empresas não constituem profissões, mas meros serviços passageiros que qualquer um pode executar. Além da farta mão de obra, as empresas conseguem ampliar sua taxa de lucro e, ao mesmo tempo, se livram dos conflitos sindicais.

Não custa dizer que essa reprodução do capital é seletiva e, ao mesmo tempo, excludente, explorando as fragilidades dos pequenos centros urbanos, revelando contradições de um processo de crescimento que não se deu de forma homogênea. Nas pequenas cidades do Nordeste brasileiro, por exemplo, essas contradições são bem mais acentuadas por serem historicamente administradas por clãs familiares detentores de terra e capital, descompromissadas com o desenvolvimento local, interessados apenas em assegurar seus privilégios.

Segundo Santana (2010), é um poder personificado na convivência próxima entre os habitantes, é nesses espaços que as ideias, preconceitos e valores dos ricos são assimilados facilmente pela população pobre. Esses núcleos urbanos eram as cidades dos notáveis, mas hoje, segundo Santos (2013), seu conteúdo mudou, passando a ser as cidades econômicas, com ramificações do sistema bancário agindo numa trama de relações que ultrapassam o lugar.

Mas, mesmo assim, as contradições nesses espaços urbanos ainda são facilmente identificadas com desenvolvimento desigual e contraditório, com classes sociais distintas utilizando os mesmos ambientes, o que favorece relações de amizades entre pobres e ricos, especialmente, nas cidades nordestinas. É comum os laços de compadrio, os filhos sendo oferecidos como afilhados a pessoa de nível social superior ao dos pais. Para Oliveira (1985), são laços estabelecidos pelo batismo católico, estabelecendo uma relação de subordinação e proteção. É basicamente um meio de sobrevivência, qualquer meio para se obter vantagens, inclusive, pela via religiosa que tona-se indispensável.

As pequenas cidades nordestinas tinham como principal característica, até bem pouco tempo, carências de recursos materiais e humanos, o que tornava difícil a sua própria autonomia socioeconômica, sendo dependentes de quase tudo, obrigadas a recorrerem a outras regiões, situação que vem se modificando. No presente, muitas 
pequenas cidades apresentam desafios semelhantes aos existentes nas cidades médias, a diferença sendo a dimensão. Além de apresentarem carências em alguns setores, assim como a ausência de equipamentos urbanos ou serviços básicos, desempenham papéis urbanos muito restrito, com uma população de renda familiar baixa.

Além disso, dificilmente conseguem gerar receitas internas, ficando dependentes de transferências externas. O poder público municipal atua como o principal empregador e também como agente executor de assistência social, procurando garantir a população de baixa renda o acesso aos bens básicos. As prefeituras aparecem como principal indutor da geração de emprego, mesmo com pouco orçamento.

As assimetrias no Brasil são um problema crônico e complexo, atravessando gerações, graças a uma escravidão que, como bem diz Santos (1997), marcou o território, os espíritos e marca, ainda hoje, as relações sociais desse país, pois, mesmo com o extraordinário progresso das ciências e das técnicas, as cidades são verdadeiros bolsões de pobreza.

Nas pequenas cidades, a falta de dinamicidade econômica agrava ainda mais a situação, com grande parcela de homens e mulheres desempregados, compondo um quadro sistêmico de famílias vivendo no berço da miséria, dependendo de políticas compensatórias como a do PBF que, na maioria dos casos, tem sido a única fonte de renda, mas uma possibilidade de paulatinamente tirar o pobre da condição de miséria, a partir do momento em que passa a ser executado em sintonia com outros programas.

O benefício concedido pelo PBF é o que Gomes (2001), no livro 'Velhas Secas em Novos Sertões', classifica de economia sem produção, que compreende a transferência de renda sem a exigência de qualquer prestação de serviço. Esse benefício é hoje um importante recurso econômico no semiárido nordestino, repassando uma considerável soma em dinheiro nas pequenas cidades, o que tem atraído cada vez mais a atuação de agentes externos interessados em abocanhar uma parte desse capital. É o que analisamos, sob o prisma da geografia, ou seja, os efeitos dessa política pública na vida dos beneficiários e os impactos da presença desses agentes externos nas cidades de Alcântaras e Frecheirinha.

\section{As cidades de Alcântaras e Frecheirinha: repercussões do Bolsa Família}

Alcântaras e Frecheirinha, juntamente com outras 16 cidades, compõem a 
Região Metropolitana de Sobral-RMS ${ }^{3}$ (Mapa 1), criada pela Lei Complementar $N^{\circ}$ 168, de 27 de dezembro de 2016. A RMS apresenta uma grande disparidade entre as cidades, com baixos índices de desenvolvimento, o que configura um quadro assimétrico, tendo a cidade de Sobral como a que exerce mais influência e principal polo industrial, atendendo mais de 54 cidades do seu entorno.

Mapa 1- Região Metropolitana de Sobral - Ceará - 2019

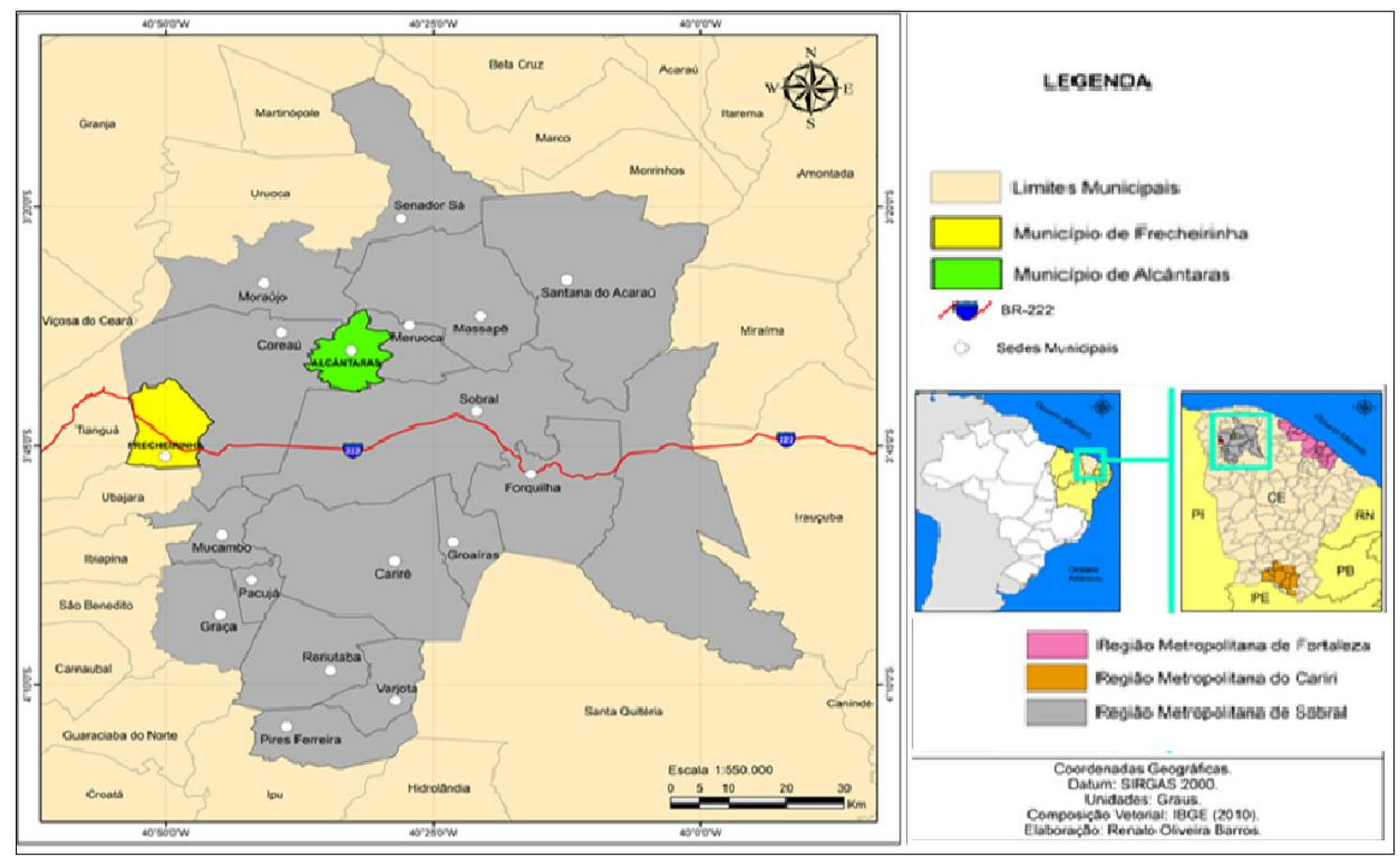

Fonte: Barros (2019).

Alcântaras está localizada na Serra da Meruoca, com forte ocupação de sua população voltada à atividade agrícola; tem como principal via de acesso a CE 240; faz divisa com Coreaú, Moraújo, Sobral, Meruoca e Massapê. Segundo os dados do Instituto Brasileiro de Geografia e Estatística (IBGE, 2010), abriga uma população de 10. 771 habitantes. Seu PIB é apenas o $170^{\circ}$ no ranque estadual, com um IDHM de 0,600 .

De acordo com os dados do IPECE (2017), Alcântaras tem apenas 915 empregos formalizados; não há indústria e o principal empregador é o setor público; a agricultura também é importante para a sua economia. A administração pública é a maior empregadora, com patamares acima de $90 \%$, praticamente de todo o trabalho ofertado

\footnotetext{
${ }^{3}$ Para saber mais sobre as 18 cidades que compõem a Região Metropolitada de Sobral, acesse o link: http://www.pduisobral.com.br/regiao-metropolitana-de-sobral.
}

\section{3, n. 3, 2019 http://periodicos2.uesb.br/index.php/geo}


O Programa Bolsa Família em cidades pequenas do Nordeste do Brasil: o caso de Alcântaras e Frecheirinha/CE

DIOGO, B.V.; HOLANDA, V.C.C. de

formalmente. Assim, quase toda ocupação fora da esfera pública se dá no âmbito da informalidade.

Frecheirinha, como polo de confecção de moda intima, tem como importante via de acesso a BR 222; faz divisa com Tianguá, Ubajara e Coreaú. Sua população hoje é de 12.991 habitantes. Ocupa a posição de $71^{\circ}$ no ranque que mede o PIB dos 184 municípios cearenses, com um IDH de 0,604. (IBGE, 2010)

Os principais empregos formais estão na Indústria e Administração Pública. A indústria de confecção figura como o principal empregador, sendo superior a todos os postos juntos de empregos formais, representando $60 \%$ de toda a economia, com pouco mais de três mil postos de trabalhos direta e indiretamente. Apresenta um notável dinamismo econômico, impulsionado pela presença de fábricas na cidade, escoando sua produção para os mercados locais, regionais, nacionais e uma pequena fatia ao mercado internacional. Segundo os dados que constam na Elaboração do Plano Diretor de Desenvolvimento Metropolitano Integrado da Região Metropolitana de Sobral (PDDUI, 2018), em 2015, Frecheirinha faturou com exportações o montante de 641 mil dólares.

Embora as duas cidades demograficamente se aproximem, Frecheirinha aparece com uma economia mais dinâmica e desponta numericamente em relação à dinâmica comercial, serviços e circulação. Quando comparada a população em situação de pobreza e extrema pobreza, os índices apresentados refletem outra realidade, como veremos a seguir.

Em Alcântaras, dos 10.771 habitantes do município, 1.081 famílias são beneficiárias do PBF, contabilizando 2.421 pessoas, o que equivale a 22,47\% da população, sendo que 2.175 pessoas vivem na extrema pobreza. (IBGE, 2010)

Já Frecheirinha tem uma população de 12.991 habitantes, dos quais 7.166 são beneficiárias, equivalente a 52,09\% da população total, (BRASIL, PBSM, 2018). No município, registra-se 3.178 pessoas vivendo na extrema pobreza. São números bem superiores a Alcântaras, levando-se em conta que a população dos dois municípios são quase próximas. Frecheirinha, embora tenha em seu território, a presença de indústrias, apresenta um elevado número de pessoas dependentes do benefício, sendo pouco mais que o dobro dos beneficiários de Alcântaras.

Os dados referentes às duas cidades são bastante significativos, revelando suas diferenças e similaridades, principalmente quando se olha para Frecheirinha com toda oferta de empregos em seu território, mesmo assim, a quantidade de pessoas em 
O Programa Bolsa Família em cidades pequenas do Nordeste do Brasil: o caso de Alcântaras e Frecheirinha/CE

DIOGO, B.V.; HOLANDA, V.C.C. de

situação de vunerabilidade social é superior a Alcântaras. Nem sempre a presença de indústria é sinônimo de prosperidade, como constatou Castel (1998), ao concluir que a pobreza é mais acentuada nos países industrializados; a causa não é ausência de trabalho, pelo contrário, é a organização dele que causa isso. $\mathrm{O}$ trabalhador sofre com a instabilidade no trabalho, não sabe se amanhã tem seu emprego e a sua mão de obra é cada vez mais desvalorizada.

Santos (1987), ao tratar a questão do salário mínimo, diz que ao invés de está ligado à dignidade do trabalhador e sua família, é tratado como um problema contábil das empresas, o que contraria a própria Constituição, que, por sua vez, assegura que todo trabalhador tem o direito a um salário justo. Pode-se dizer que Frecheirinha sintetiza bem os reflexos desse 'problema contábil', mesmo com uma maciça presença da indústria e com mais de três mil postos de trabalho, responsável por $60 \%$ de toda a sua economia, supera Alcântaras no quesito pobreza. Isso só comprova que a presença de indústrias não é garantia de qualidade de vida para a população local.

Compreender suas dinâmicas não é tarefa simples, como defende Santos (1985), já que estudar o pequeno é mais difícil porque tudo que se manifesta em seu espaço são estímulos de várias ordens. Já vimos que analisa-las sob a ótica da presença ou ausência de indústria em seu território é insuficiente para compreender suas dinâmicas. Ao analisarmos o peso das transferências do PBF, nos últimos cinco anos, temos uma noção da importância dessa política pública para as famílias beneficiárias, como podemos verificar (Quadro 1) nos valores repassados entre 2015 até agosto de 2019.

Quadro 1 - Repasse do Programa Bolsa Família de 2015 a 2019.

\begin{tabular}{|l|r|}
\hline \multicolumn{1}{|c|}{ ALCÂNTARAS } & FRECHEIRINHA \\
\hline Valor anual/ 2015- R\$ 2.496, 211,00 & Valor anual/ 2015- R\$ 4.544, 427,00 \\
\hline Valor anual/ 2016-R\$ 2.099, 812,00 & Valor anual/ 2016-R\$ 4.641, 880,00 \\
\hline Valor anual/ 2017-R\$ 1.810, 805,00 & Valor anual/ 2017- R\$ 4.881,169, 00 \\
\hline Valor anual / 2018-R\$1.899.503,00 & Valor anual / 2018-R\$ 5.055.205,00 \\
\hline Valor anual repassado até agosto/2019 & Valor repassado até agosto/2019 \\
$\mathrm{R} \$ 1.328,893,00$ & $\mathrm{R} \$ 3.468 .208,00$ \\
\hline
\end{tabular}

Fonte: Ministério da Cidadania, Folha de Pagamento do Programa Bolsa Família (Agosto/2019). 
As cifras repassadas nas duas cidades mostram o peso e a importância desse recurso para as famílias pobres e, principalmente, para o comércio nas duas cidades. Outro dado importante é que a prevalência de pessoas em situação de pobreza em Frecheirinha não é advinda de crises na indústria local, pelo contrário, nos últimos cinco anos, o repasse às famílias carentes permaneceu praticamente o mesmo, na casa dos quatro milhões de reais por ano, indicando que o número de pessoas em situação de vulnerabilidade social, nesse período, teve poucas alterações.

Em Alcântaras, embora o valor repassado seja menor que em Frecheirinha, o repasse também permanece com poucas oscilações, na casa dos dois milhões anuais. A intensidade das oscilações entre as duas cidades proporcionalmente seguem a mesma frequência, o que evidencia que, nesse intervalo de tempo, houve poucas mudanças em relação a quantidade de pessoas que entram ou saem do PBF. São números que revelam a importância desse benefício e o quão é complexo deixar de depender dessa política pública nas duas cidades. Ao compará-las, observamos que pouco importa se há a presença ou ausência de empregos, a pobreza continua quase inalterável nas duas populações.

Outro aspecto importante é a quantia repassada nesses últimos cinco anos: um total transferido nas duas cidades ultrapassa facilmente a casa dos trinta milhões de reais. Em Alcântaras, o montante repassado de 2015 até agosto de 2019 chega a pouco mais de nove milhões de reais. Em Freceirinha, ultrapassa os vinte e dois milhões. São valores consideráveis e que alimentam uma forte dinâmica não só no comercio local como também nas cidades maiores ao seu entorno, como Sobral, que abriga um rico e variado comércio que abastece as demais cidades dentro da região metropolitana.

Hoje tá muito bom! Eu tenho a minha clientela certa. Aqui eu vendo de tudo. Tem a farinha, o arroz, o feijão, o guaraná, a mortadela, o frango de granja, o miojo, esses danone. E você pensa que é qualquer coisa que o povo come hoje? Eu cai na besteira de comprar uns pacotes de massa pra fazer cuscuz e até hoje está ai os pacotes do mesmo jeito. É bom, é sinal que as coisas estão melhorando; hoje o povo tem muita opção; nem parece como antigamente, que era só o feijão com farinha. Era tudo era difícil, pra você ver, quando eu precisava abastecer o meu comercio eu tinha que ir pra Sobral. Agora eu não saiu nem de casa, os vendedor vem bater na minha porta; faço 
o pedido e pronto, no outro dia tão aqui fazendo a entrega (INFORMAÇÃ $\tilde{O}$ VERBAL) ${ }^{4}$

A sua fala descreve as mudanças que vem ocorrenda na cidade de Frecheirinha. O recurso do PBF injetado na cidade proporcionaou que a população local aumentasse seu poder de compra, passando a consumir uma maior variedade de produtos. Esse aumento no consumo faz com que os comerciantes se adaptem as exigências de seus consumidores, diversificando seus produtos; criando promoções, facilitando o crédito.

Na cidade de Alcântaras também ocorre uma dinâmica semelhante, conforme nos relata o comerciante Antonio:

Qualquer comerciante aqui tem seu lucro no final do mês; tem até gente rica, pagando escola particular pros filhos, com carro na garage. Eu não troco esse meu ramo por nada. Meu pai sempre dizia que o negocio é o comercio. Antigamente o povo pagava as compras trabalhando, não tinha dinheiro. Era o povo fazendo farinha, plantando, capinando nas terras dos outros. Só enricava o dono da terra. Agora tá muito diferente, todo mundo tem o seu trocadinho. Olha, todo dia tem caminhão de Sobral fazendo entrega de mercadoria; ontem mesmo eu fiz o pedido de vinte quilo de frango congelado e dez de linguiça; não sobre nada no final de semana.(INFORMAÇÃO VERBAL) ${ }^{5}$.

Nas duas falas, observamos que é Sobral que abastece as duas cidades. Tanto em Alcântaras como em Frecheirinha, notamos que, nas falas dos comerciantes, há referência a produtos industrializados, como o guaraná (refrigerante), a mortandela, o miojo e, até mesmo, o frango congelado, a linguiça, o que mostra que a dieta nas duas cidades vem passando por transformações.

Costa e Schor (2013) ensinam que analisando o modo como as pessoas se alimentam, é possível identificar as transformações que elas vêm passando. O mesmo diz DaMatta (1984) ao afirmar que o tipo de comida consumida por uma população revela sua história e suas transformações ao longo tempo. Os produtos que vêm sendo consumidos pelas duas populações são elementos que mostram alterações culturais e econômicas, com maior variedade de produtos nas prateleiras dos comércios, o que tem dado vida e dinâmica ao comércio local.

\footnotetext{
${ }^{4}$ Entrevista realizada com Francisco, comerciante de Frecheirinha, em 5 de agosto de 2019; entrevista gravada em aparelho celular por Bertoni Vasconcelos Diogo em agosto de 2019.

${ }^{5}$ Entrevista realizada com Antonio, comerciante de Alcântaras, em 8 de agosto de 2019, entrevista gravada em aparelho celular por Bertoni Vasconcelos Diogo em agosto de 2019. 
As duas cidades incorporam novas dinâmicas com circulação diária de mercadorias, graças ao potencial público consumidor. Essa circulação de mercadorias é o que Santos e Silveira (2014) definem como circuitos espaciais de produção e do consumo, o que intensifica cada vez mais as trocas e as relações com outros territórios. A distribuição e o consumo se expandem conforme a demanda, alimentando um fluxo diário de pessoas e mercadorias, nas duas cidades.

Essas novas dinâmicas nas duas cidades sintetizam as transformações que vêm ocorrendo no território nos últimos anos. Esse é um quadro totalmente diferente da leitura feita por Josué de Castro, na década de 1940, onde afirmava que inexistia uma comunicação entre o sertão e os grandes centros localizados no litoral. Essa falta de integração foi apontada por Castro (1984) como responsável pelo sertanejo ter uma dieta com pouca variedade de alimentos.

Hoje, a realidade é bem diferente de décadas atrás, pois há uma intensa comunicação entre as cidades e uma diversidade de mercadorias circulando no território. Contudo, ainda presenciamos em Alcântaras e Frecheirinha, a permanência de antigas praticas, como a venda das mercadorias tendo como garantia a palavra do comprador. Para isso, não é preciso o dinheiro para poder fazer a compra. Segundo os comerciantes das duas cidades, muitos dos seus clientes são do PBF, conforme a necessidade da família, eles vão pegando suas mercadorias para pagar apenas no final do mês. É o tipo de venda popularmente conhecida por 'fiado'.

Segundo Guimarães (2009), esse tipo de compra é baseado na confiança que se forma através das relações sociais estabelecidas no grupo. Não é para qualquer um que se vende. Para Carvalho (1985, p. 16), “o fiado supõe relações de amizade e confiança entre as partes, envolvidas. Isto porque não há nenhum vínculo formal que gere instrumentos legais de garantia ou de coerção na cobrança dos débitos". Os valores das compras são anotados em uma caderneta, que fica, geralmente, com os comerciantes. Diante disso, podemos dizer que, nas duas cidades, existe um choque entre o global e o local, pois o 'fiado' é um tipo de venda que foge ao modelo vigente no mercado capitalista.

Como vemos, o PBF é capaz de promover novas dinâmicas por meio dos valores que são repassados para as duas cidades, também garante a permanência de práticas tradicionais como a venda com anotação na caderneta. Isso porque a condição de beneficiário é, de certa forma, uma garantia de que sempre, ao final do mês, as dívidas 
DIOGO, B.V.; HOLANDA, V.C.C. de

entre cliente e comerciante serão quitadas, o que é reforçado também pela relação de vizinhança, já que todos moram bem próximos.

Quando questionamos os beneficiários se o dinheiro ajuda, obtemos as seguintes respostas:

As vezes a gente precisa comprar um remédio pros filhos, uma coisa; tendo o dinheiro, eu não trabalho, né? Mas tem ele pra ajudar. No posto de vez em quando falta remédio. As vezes a gente precisa comprar alguns. Eu compro várias coisas; compro pra dentro de casa mesmo; alguma coisa pros meninos; eu pago energia. Antes era ruim porque faltava as coisas; a gente não tinha como comprar; o meu marido fazia algum biquin vei, recebia um trocadinho, comprava as coisas; mas não era o suficiente (INFORMAÇÃO VERBAL) ${ }^{6}$

Em sua fala percebemos a importância do PBF na vida da família. Segundo Socorro Maria, antes de receber o benefício a sua família passava muitas necessidades, faltava o básico. Ela e os filhos viviam na incerteza se teriam o que comer no dia seguinte, pois dependiam da sorte do marido conseguir algum emprego temporário. Mas o emprego não era a garantia de quase nada; logo logo seu esposo estaria novamente desempregado e as dificuldades continuariam as mesmas. As coisas só mudaram quando a família passou a receber o beneficio. Hoje a família tem a certeza que não passarão fome.

Para Joana, moradora de Alcântaras, o PBF é também uma grande ajuda. É um dinheiro que garante a sobrevivência da sua família, diz ela:

Me ajuda. É um dinheirinho que é certo. Mesmo sabendo que esse valorzinho é pouco, mas é um dinheiro certo. Eu mesma faço muita coisa com esse dinheiro; antes eu não podia comprar no comercio porque eu não tinha como pagar. Hoje os comerciantes fazem é perguntar se eu não vou comprar nada. As coisas mudaram. O Bolsa Família é uma ajuda que a gente tem pra se manter, porque aqui não tem emprego. É muito difícil. O Bolsa Família salvou muita gente. A gente que não tem emprego, como o meu marido que está sem trabalhar, a gente depende mesmo desse dinheiro. O Bolsa Família é uma forma de você está sobrevivendo. (INFORMAÇÃO VERBAL). ${ }^{7}$

\footnotetext{
${ }^{6}$ Entrevista realizada com Socorro Maria, beneficiária e moradora de Frecheirinha, em 6 de agosto de 2019; entrevista gravada em aparelho celular por Bertoni Vasconcelos Diogo em agosto de 2019.

${ }^{7}$ Entrevista realizada com Joana, beneficiária e moradora de Alcântaras, em 8 de agosto de 2019; entrevista gravada em aparelho celular por Bertoni Vasconcelos Diogo em agosto de 2019.
} 
Podemos ver que o PBF traz um alívio para as pessoas que vivem na linha de pobreza; cada centavo é gasto pensando nas necessidades da casa. É um valor pequeno, mas que assume um significado enorme em suas vidas, que segundo a propria Joana, garante a sobrevivência da sua família. A sua história retrata a vida milhares de famílias brasileiras, que ao passarem a receber o benefício sentiram uma melhora em suas vidas, tendo uma garantia que seus filhos não irão dormir com fome.

Para as famílias beneficiárias, o PBF não representa apenas um auxílio do Governo Federal, representa bem mais que isso. O benefício é uma garantia de sobrevivência, garantia de que a sua família vai ter o que comer durante o dia. Não é um valor destinado a compra de bens supérfluos, mas sim compra de itens básicos. Tanto em Alcântras como em Frecheirinha, o dinheiro repassado pelo programa é um patrimônio da família, pois as compras são pensadas conforme as necessidades da casa.

Embora seja um valor relativamente pequeno, ele garante que as famílias tenham alguma dignidade e elevem sua autoestima, podendo realizar compras no comércio local, mesmo que estejam desempregados. Hoje, as famílias conseguem comprar gêneros alimentícios. Nesse sentido, o PBF é uma renda que movimenta a economia das duas cidades, gerando emprego e renda, além de impactar positivamente na vida das famílias pobres das duas cidades, garantindo, conforme já pontuamos dignidade e acesso a bens básicos.

\section{Considerações finais}

Neste estudo, constatamos que, através dos recursos transferidos pelo governo federal, as famílias beneficiárias do PBF das cidades de Alcântaras e Frecheirinha passaram a ter acesso a novos hábitos de consumo. Essa mudança nos padrões de consumo se confirma na presença de novos produtos nas duas cidades, como, por exemplo: produtos industrializados, em conserva, aparelhos eletroeletrônicos, roupas e cosméticos, além de ser um programa eficaz na redução da pobreza, com efeitos positivos na melhoria das condições de vida das famílias, contribuindo para a qualidade de vida e bem-estar da população.

Embora sejam duas cidades com atividades econômicas distintas, observamos que as transferências de renda representam uma fonte de rendimento as famílias. Tal renda é utilizada na aquisição de bens e serviços, gerando lucro ao comercio local e das 
O Programa Bolsa Família em cidades pequenas do Nordeste do Brasil: o caso de Alcântaras e Frecheirinha/CE

DIOGO, B.V.; HOLANDA, V.C.C. de

cidades vizinhas. Essa rotatividade tem impulsionado a economia, gerando emprego e renda no comercio local e nas cidades vizinhas, como Sobral, que escoa parte de suas mercadorias, o que comprova que os impactos do PBF atingem beneficiários e não beneficiários.

O PBF também favorece uma relação de confiança entre comerciantes e beneficiários, cuja venda/compra de gêneros alimentícios é feita sem que haja a necessidade de pagar na hora, mediante um contrato verbal entre comprador e vendedor, como constatamos nas duas cidades.

Por fim, ressaltamos a importância de se estudar como as políticas públicas se comportam no território, pois fornecem uma série de elementos importantes para o geógrafo fazer uma leitura do espaço onde elas estão presentes. Afinal, as políticas públicas possuem vinculação direta com o espaço que é um elemento dinâmico, transformando a geografia dos territórios, produzindo novas formas espaciais e novos significados.

\section{Referências}

ALEGRE, Marcos. Aspectos do fato urbano no Brasil: análise quantitativa pelo método cartográfico. Presidente Prudente: Faculdade de Filosofia, Ciências e Letras da Unesp de Presidente Prudente, 1970.

BARROS, R. P. de et al,.Determinantes da queda da desigualdade de renda no Brasil. Rio de Janeiro: Ipea ,2010 (Texto para Discussão, n. 1.460).

BEAUJEU-GARNIER, Jacqueline. Geografia Urbana. Fundação Caloutes Gulbenkian, Lisboa, 1980.

BRASIL, Constituição (1988). Constituição [da] República Federativa do Brasil. Brasília: Senado Federal, 1988.

BRASIL. Ministério do Desenvolvimento Social e Agrário: Relatório de Informações Sociais RI. Disponível em: https://aplicacoes.mds.gov.br/sagi/ri/relatorios/mds/index.php. Acesso em: ago.2019.

BRASIL. Plano Brasil Sem Miséria- PBSM. Disponível em: http://aplicacoes.mds.gov.br/sagirmps/ferramentas/nucleo/grupo.php?id_grupo=69. Acesso em 08 de junho de 2018.

CASTEL, Robert. As metamorfoses da questão social: uma crônica do salário. Petrópolis, RJ: Vozes, 1998.

CASTRO. Josué de. Geografia da Fome: o dilema brasileiro: pão ou aço.- Rio de Janeiro, 1984. 
COSTA, Ellem A. C; SCHOR, Tatiana. Redes Urbanas, Abastecimento e o café da manhã de idosas na cidade de Tefé. Amazonas: Elementos para a análise de Alimentação no Brasil. In: Hygeia, Uberlândia v. 9, n. 17, p. 52-73, dez, 2013.

DAMATTA, Roberto. O que faz o Brasil, Brasil?. Rio de Janeiro: Editora Rocco, 1984.

EIDELWEIN, Karen. Economia Solidária: a produção dos sujeitos (des)necessários. Jundiaí, Paco Editorial: 2011.

GOMES, G. M. Velhas secas em novos sertões: continuidade e mudanças na economia do semi-árido e dos cerrados nordestinos. Brasília: Ipea, 2001.

IANNI, Octávio. O príncipe eletrônico. Departamento de Filosofia e Ciências HumanasUnicamp- 13081-970- Campinas- SP. Perspectivas, São Paulo. 22: 11-29, 1999.

IBGE- Instituto Brasileiro de Geografia e Estatística. Censo Demográfico 1991. Disponível em: http:// http://www.ibge.gov.br/home/estatistica/populacao/censo2000. Acesso em maio de 2019.

IBGE. Instituto Brasileiro de Geografia e Estatística. Arranjos Populacionais e Concentrações Urbanas no Brasil. (2016). Disponível em:

http://biblioteca.ibge.gov.br/index.php/bibliotecacatalogo?view=detalhes\&id=299700. Acesso em abr. 2019

IBGE. Instituto Brasileiro de Geografia e Estatística. Censo Demográfico 2000. Disponível em: http:// http://www.ibge.gov.br/home/estatistica/populacao/censo2000. Acesso em maio de 2019.

IBGE. Instituto Brasileiro de Geografia e Estatística. Cidades@. Disponível em: $<$ http://cidades.ibge.gov.br/painel/painel.php?codmun=230050>. Acesso em: 07/05/ 2019.

IPEA- INATITUTO DE PESQUISA ECONOMICA APLICADA. A década inclusiva (2001- 2011): desigualdade, pobreza e políticas de renda. Brasília: Ipea, 25 set. 2012. (Comunicados do Ipea, n.155).

IPECE - Instituto de Pesquisa Econômica e Estratégia do Ceará. Perfil Básico Municipal - PBM 2017: Alcântaras. Disponível em: http//: www.ipece.gov.ce. Acesso em 12/09/2018.

IPECE. Perfil Básico Municipal - PBM 2014: Frecheirinha. Disponível em: http//: www.ipece.gov.ce. Acesso em 12/90/2018.

JANNUZZI, Paulo de Martino; PINTO, Alexandre Rodrigues. Bolsa Família e seus impactos nas condições de vida da população brasileira: uma síntese dos principais achados da pesquisa de avaliação de impactos do Bolsa Família II. In: CAMPELLO, T.; NERI, M. C. (Org.). Programa Bolsa Família: uma década de inclusão e cidadania. Brasília, DF: IPEA, 2013. p. 179-192. 
OLIVEIRA, Pedro de. Religião e dominação de classe: gênese e função do catolicismo romanizado no Brasil. Editora Vozes. Petrópolis, 1985.

REGIÃO METROPOLITANA DE SOBRAL- RMS. Disponível em: http://www.pduisobral.com.br. Acesso em 07 de abril de 2019.

SANTANA, Antonia Neide Costa. O urbano no semiárido: pequenas cidades do Ceará em discussão. In: FREITAS, Nilson Almino de; JÚNIOR, Marta Maria; HOLANDA, Virgínia Célia Cavalcante (organizadores) Múltiplos olhares sobre a cidade e o urbano: Sobral e Região em Foco. Sobral: UECE/UVA, 2010.

SANTANA, Jomar Álace. A evolução dos programas de transferência de renda e o Programa Bolsa Família. Seminário População, Pobreza e Desigualdade, Anais... Belo Horizonte, p. 1-19, 2007.

SANTOS, Milton. O período técnico-científico e os estudos geográficos. Revista do Departamento de Geografia da USP, São Paulo, v.4, p.15-20, 1985.

SANTOS, Milton. A redescoberta da Natureza. Revista Estudos Avançados, Universidade de São Paulo, V. 6, n. 14, jan/abril, 1992.

SANTOS, Milton A Natureza do Espaço: Técnica e tempo, Razão e Emoção.- 4. ed. São Paulo: Editora da Universidade de São Paulo, 2006.

SANTOS, Milton. A responsabilidade social dos geógrafos. Jornal de geografia, Uberaba, out, 1985.

SANTOS, Milton. A Urbanização Brasileira.-5. ed., 3. reimpr.- São Paulo: Editora da Universidade de São Paulo, 2013.

SANTOS, Milton As cidadanias mutiladas. In: LENAR, Julio (org.). O preconceito. São Paulo. Imprensa Oficial do Estado, 1997.

SANTOS, Milton. Metamorfose do espaço habitado. São Paulo: Editora da Universidade de São Paulo, 2014.

SANTOS, Milton. O espaço do cidadão.- São Paulo: Nobel, 1987.

SANTOS, Milton. O Período Técnico-científico e os Estudos Geográficos. Geografia 4: 15-20, 1990.

SANTOS, Milton. O Trabalho do Geógrafo no Terceiro Mundo.- 5. ed. São Paulo: Editora da Universidade de São Paulo, 2013.

SANTOS, Milton. Por uma outra globalização: do pensamento único à consciência universal.-22a . ed.- Rio de Janeiro: Record, 2012.

SANTOS, Milton; SILVEIRA, Maria Laura. O Brasil: território e sociedade no início do século XXI. - 18 ${ }^{\mathrm{a}}$ ed.- Rio de Janeiro: Record, 2014.

SILVA, M. Ozanira da Silva e; GUILHON, Maria Virgínia Moreira. O Bolsa Família no contexto da proteção social: significado e realidade das condicionalidades e do 
O Programa Bolsa Família em cidades pequenas do Nordeste do Brasil: o caso de Alcântaras e Frecheirinha/CE

DIOGO, B.V.; HOLANDA, V.C.C. de

Índice de Gestão Descentralizada no Estado do Maranhão. In: Ministério do Desenvolvimento Social e Combate à Fome. (Org.). Avaliação de políticas públicas: reflexões acadêmicas sobre o desenvolvimento social e o combate à fome. Brasília: MDS, 2014, p. 75-99.

WEISSHEIMER, Marco Aurélio. Bolsa Família: avanços, limites e possibilidades do programa que está transformando a vida de milhões de famílias no Brasil. São Paulo: Editora Fundação Perseu Abramo, 2006. 